International Journal of Advanced Academic Studies 2020; 2(3): 116-120

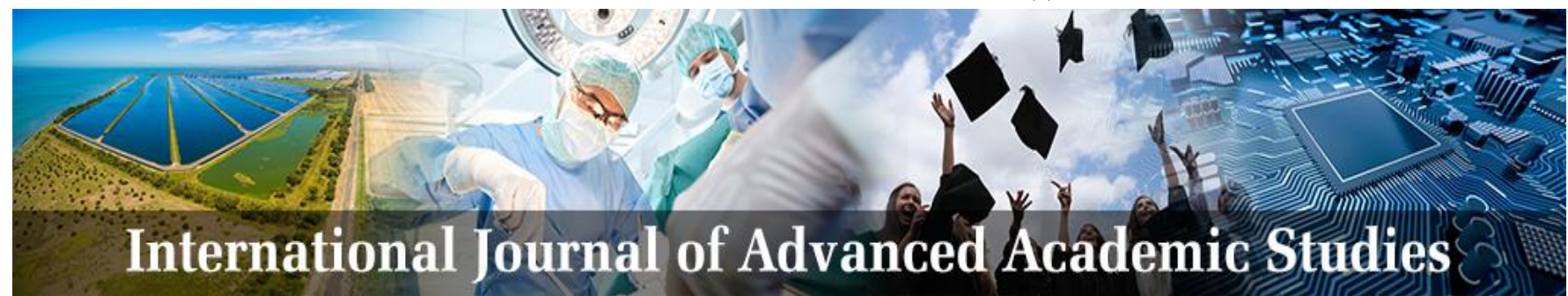

E-ISSN: 2706-8927

P-ISSN: 2706-8919

Www.allstudyjournal.com IJAAS 2020; 2(3): 116-120

Received: 13-05-2020

Accepted: 15-06-2020

دوكتور عبدالواحد لياقت الاستاذ: بكلية الثريعة جالئو جامعة بغلان |فغانستان:
تعريف اللقطة في الفقه الاسلامي

دوكتور عبدالواحد لياقت

DOI: https://doi.org/ 10.33545/27068919.2020.v2.i3b.136

فإن الثريعة المطهرة قد اشتملت على ما فيه صلاح العباد في الدارين , فقد شرع الله تعالى لعباده

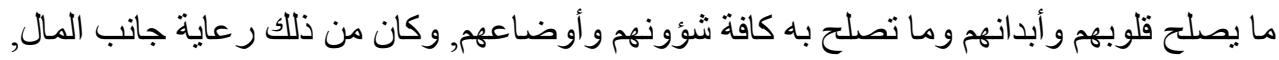

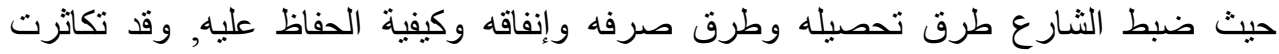

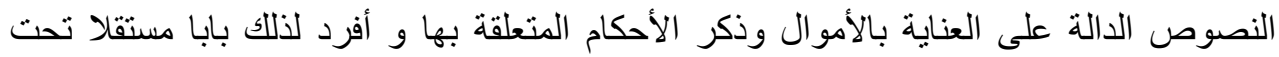
عنوان اللقطة فيه أحكام تستند إلى الادلة الثر عية.

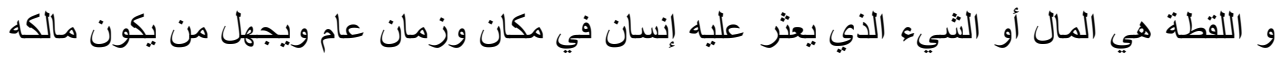

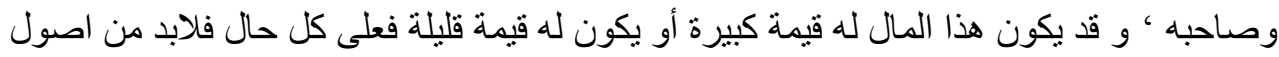

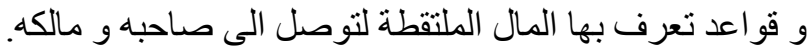

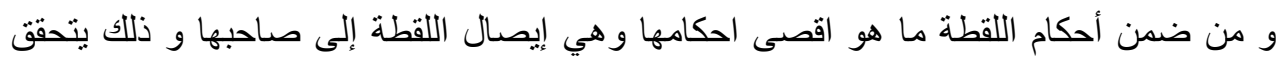

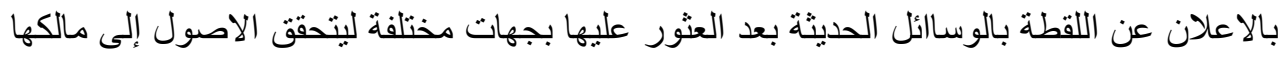

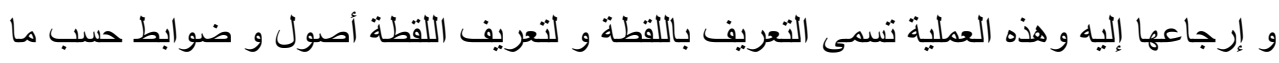

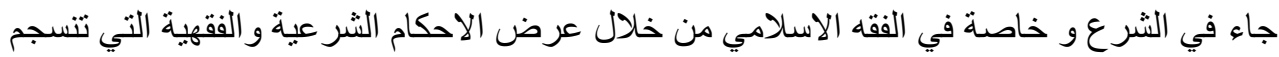

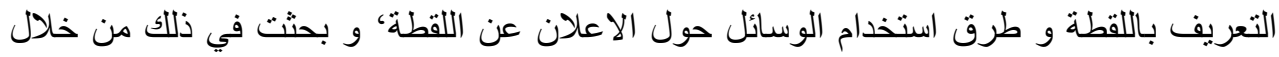

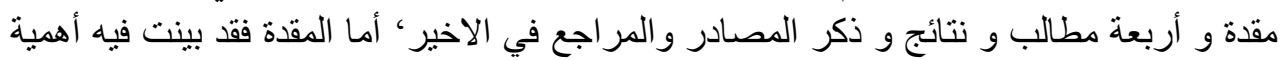

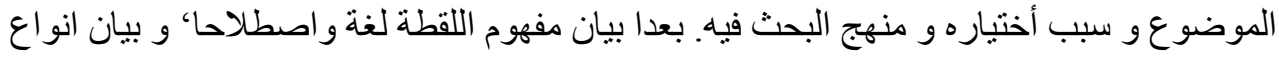

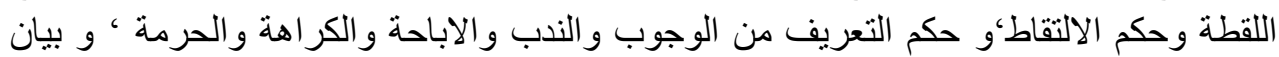

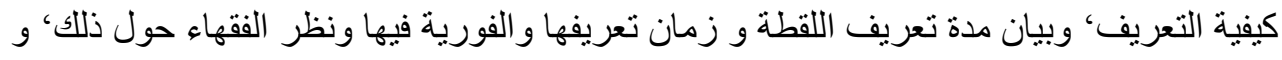

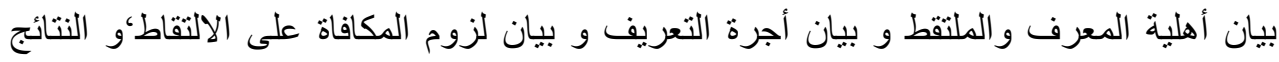

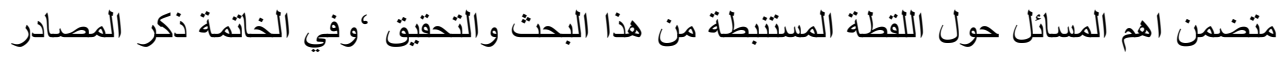

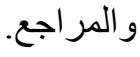

الكلمات الاساسي: اللقطة ، الملتقط · تعريف.'الاعلان' وسائل، الفقه الاسلامي.

المقدمة

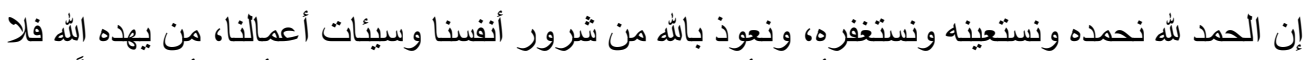

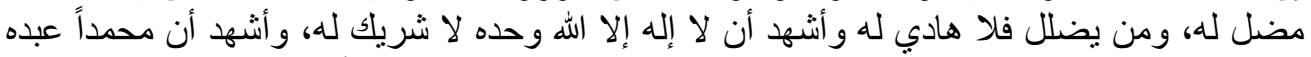

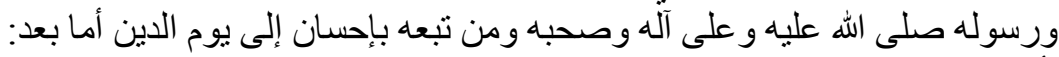

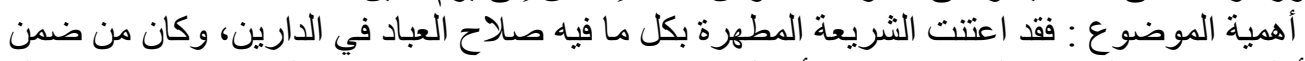

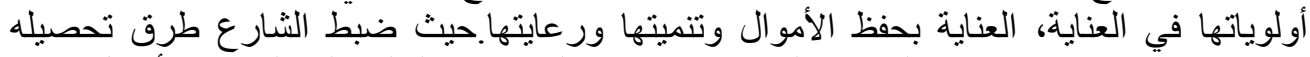

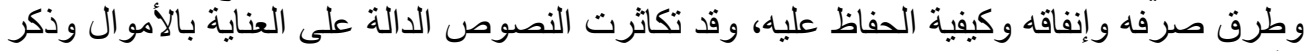

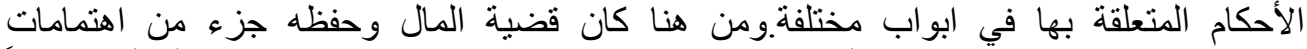

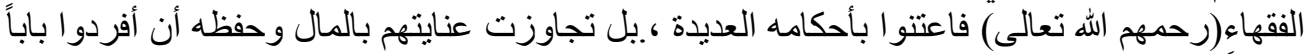

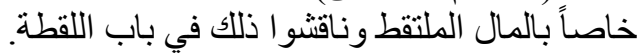


هدف البحث: فقد رايت مناسبا أن أبين تعريف اللقطة وطرقه و

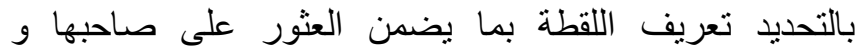
إيصالها 'و إعادنها اليه ' و أذكر كل الطرق و و الجهات المدكنة

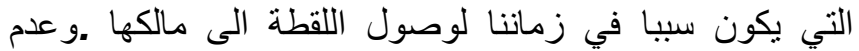

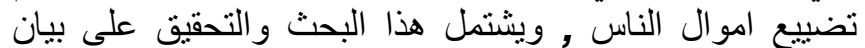
ماهو ضرورة الاعلان عن اللقطة ' و بيان مفهوم اللقطة لغة لغنة

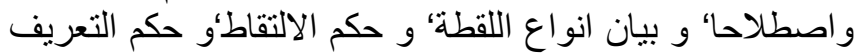

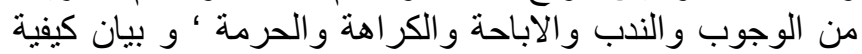

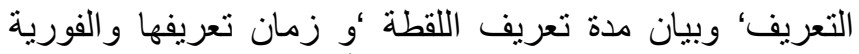

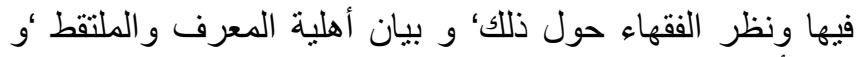

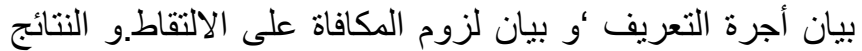

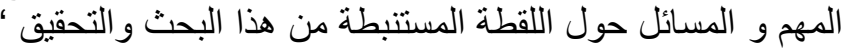
وفي الخاتمة ذكرت المصادر و المر اجع. ومن الله التوفيق.

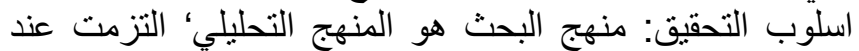

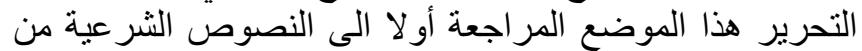

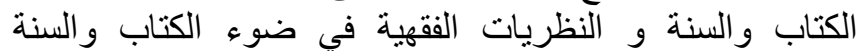

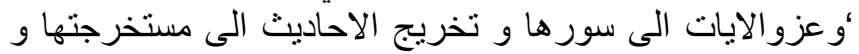

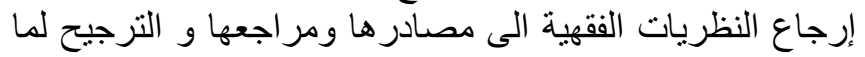
هو اولى حسب الادلة الثرعية.

\section{تعريف اللقطة:}

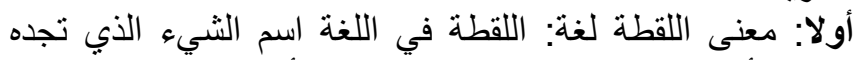

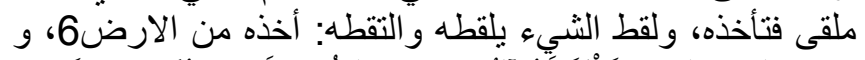

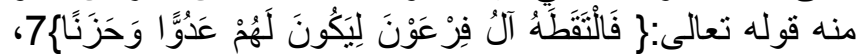

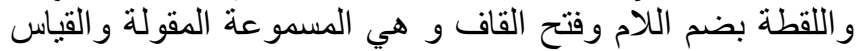

$$
\text { تسكين الكاف } 8 .
$$

ثانيا: اصطلاحا : اللقطة : مال يوجد على الارض لا لا يعرف له له

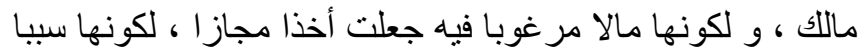

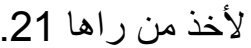
و في اصطلاح القانونين: الاموال والاشياء المنقولة مما يجوز

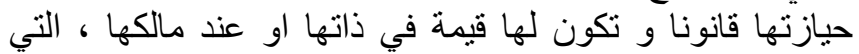

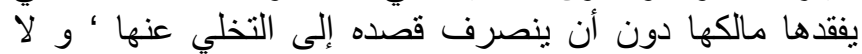

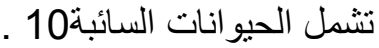

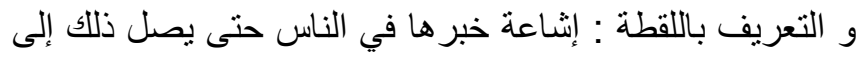

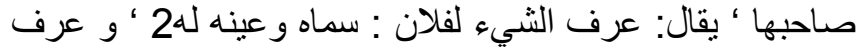

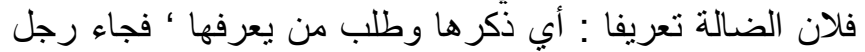

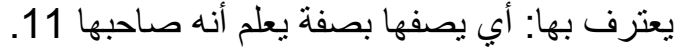

\section{أنواع اللقطة:} المال الملتقط بشكل عام إما أن بكون حيو انا فيسمى (ضالة )وأو

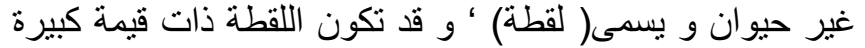

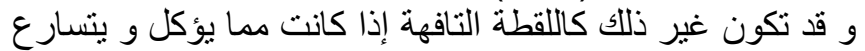

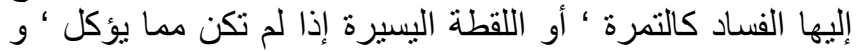

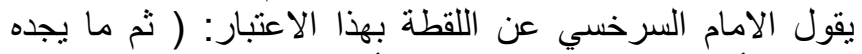
نو عان( أحدهما ) ( و الثناني) ما يعلم أن مالكه يطلبه) 12. و اللقطة لها صور عدة :

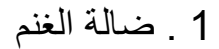
2 1 ـ ضالة الابل الغن

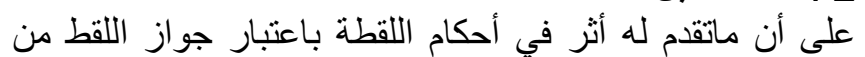

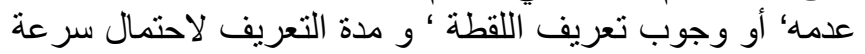

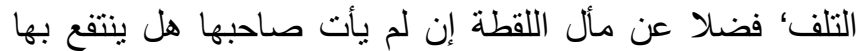

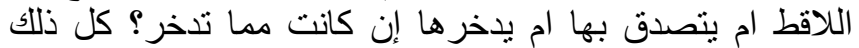

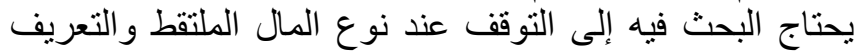
على خصوصيته للحفاظ عليه قدر المستطاع.

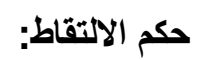

إختلف الفقهاء في ذللك على القولين:

القول الاول: كراهة أخذ اللقطة والترك أفضل ألفرل أعدم أخذها افضل

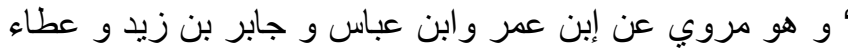

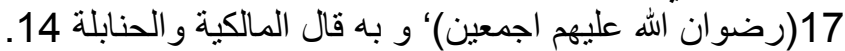

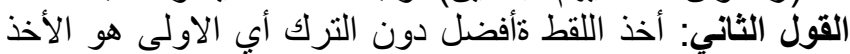

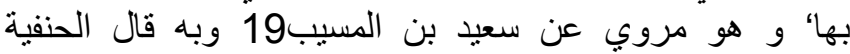

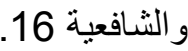

و استدل المانعون بما رواه الجارود العبدي(رضي الله عنه) أن الن الني

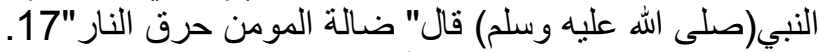

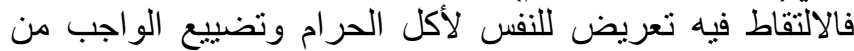

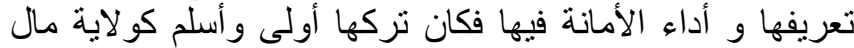

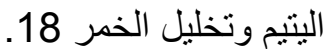

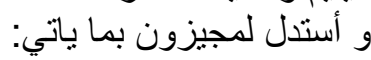

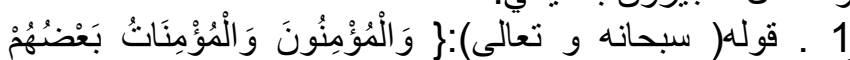

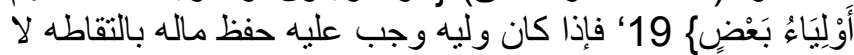

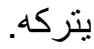
1

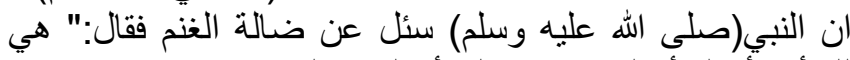

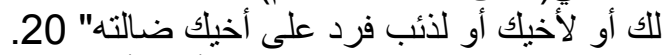

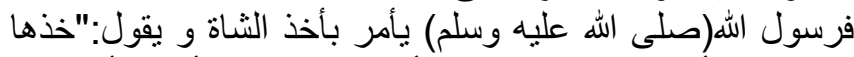

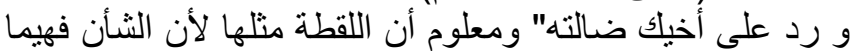

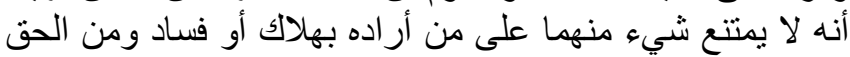

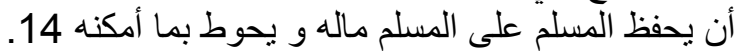
و قد يكون اللقط دائر العى الاحكام التكليفية الخمسة على النحو الاتي: 1.اللقط الواجب : و هو إذا خيف على المال الضائع يجب اللقط ل للحفاظ عليه!

1.اللقط المندوب: و هو عو عند عدم الخوف على المال الضائع إذا

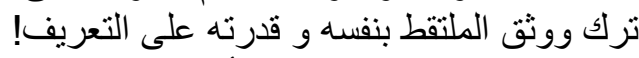

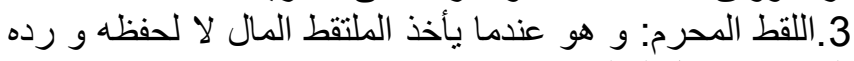
إلى صاحبه بل لتملكها! 4.اللقط المكروه: و هو إذبا التما التقط المال من بثك في أمانة نفسه

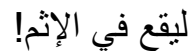
5.اللقطّ المباح: و هو إذا إستوى الترك و الاخذ باعتبار ماتقدم21.

\section{حكم التعريف:} اولا: وجوب التعريف:

يجب تعريف اللقطة باتفاق جمهور الفقهاء 22.

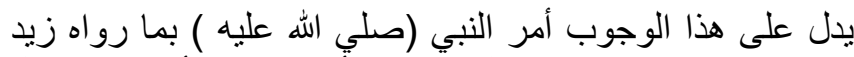

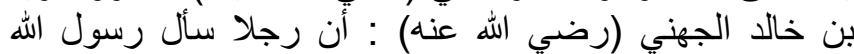

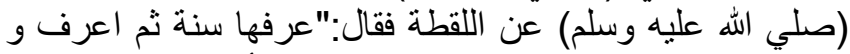

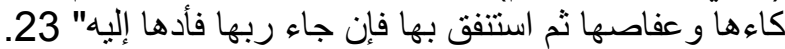

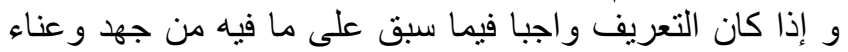

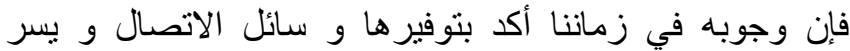

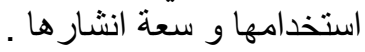
و يستتنى من التعرف والنعار والاعلان باللقطة مايأتي:

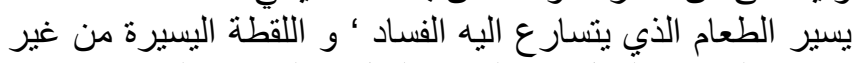

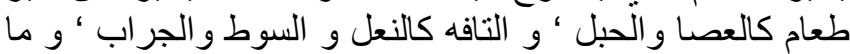

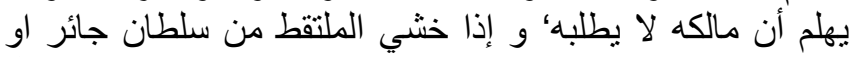

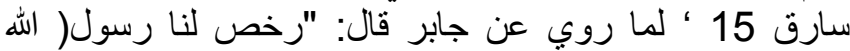

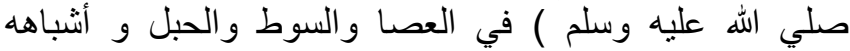

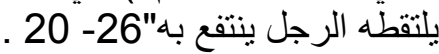




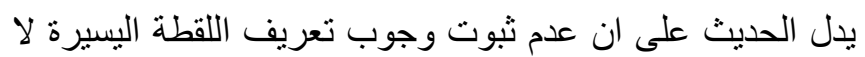

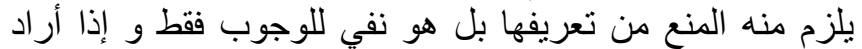
الملتقط تعريفها فلا مانع فيها.

\section{ثانيا: كيفية تعريف اللقطة:} لما كان الغرض من تعريف تلفريف اللقطة ايصالها الى مالكها ' وجب

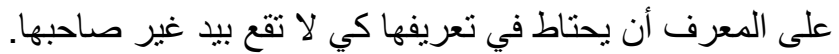

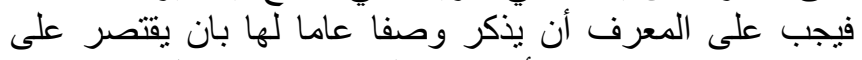

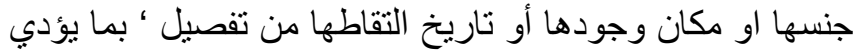

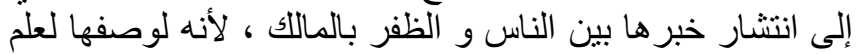

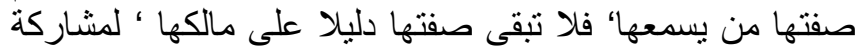

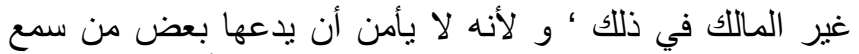

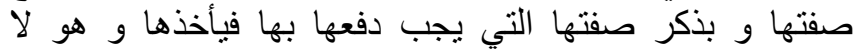
يملكها فتضيع على مالكها 18 و الابهام في التعريف يهدف الى تلى تحقيق أمرين:

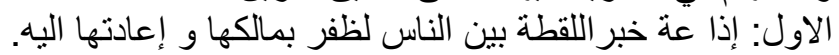

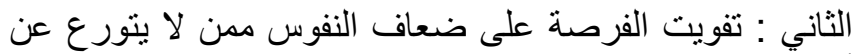

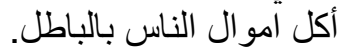

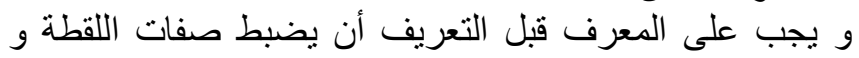

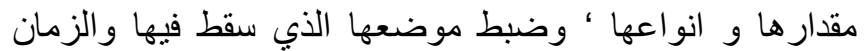

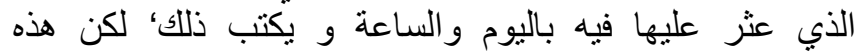

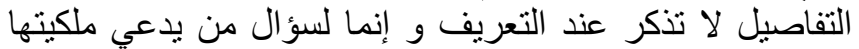

فإذا وصفها وصفا دقيقا عرف أنه صاحبها و مالكها فتدفع إليه.

\section{مدة التعريف و الفورية فيه:} اولا: مدة التعريف و زمنه:

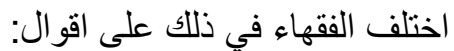
القول ألاول: تعرف اللقطة سنة كاملة مهما كان شأنها 'و و هو مروي عن عمر وعلي وابن عباس (رضي الله عنهم) ' و به قال الهال

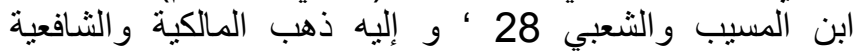
و الحنابلة والظاهرية 29 والئين

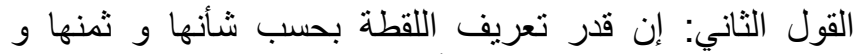

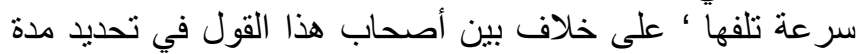

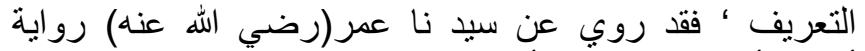

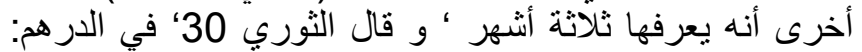

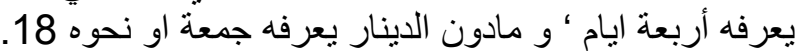

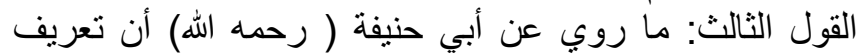

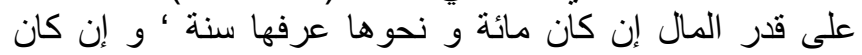

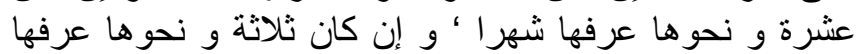
جمعة او قال عشرة ' و إن كان درهما و نحوه ندان عرفه ثلاثنة ايام

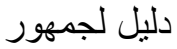
إستدل الجمهور بما رواه زيد بن خالد الجهني( رضي الله عنه) : أن رجلا سأل رسول الله (صلى الله عليه وسلم) عن اللقطة فقال:"

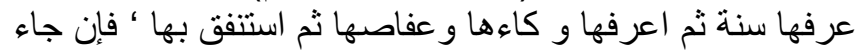

ربها فأدها إلي نائ اعرفا 18.

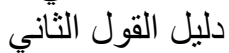
إستدل اصحاب القول الثاني بن بمائني:

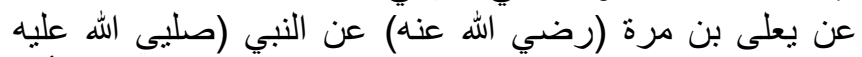

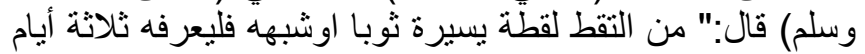

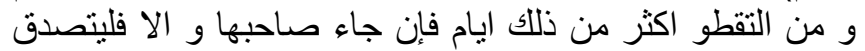

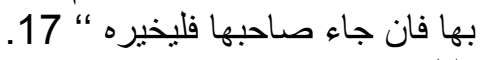
دليل الامام ابي حنيفة
و استدل الامام ابوحنيفة بما رواه عطاء بن يسار عن ابي سعيد

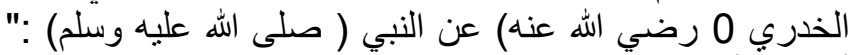

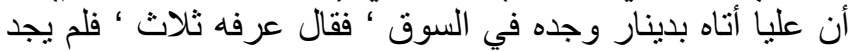
من يعرفه ، فرجع إلى النبي ( صلى اللى الله عليه وسلم) فاخبره فقال:

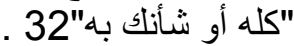

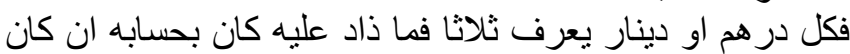

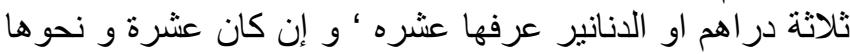

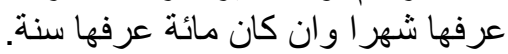

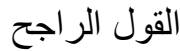

و الراجح في الرايي هو أن مدة الكثير من اللقطة هو سنة كاملة ، لإنة

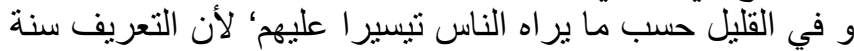

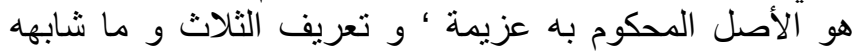

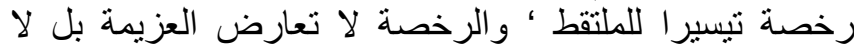

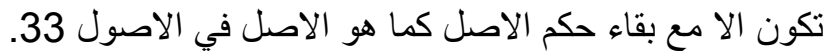

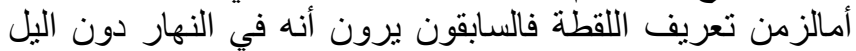

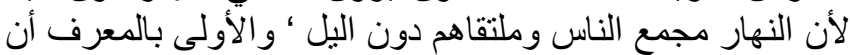

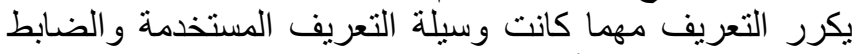

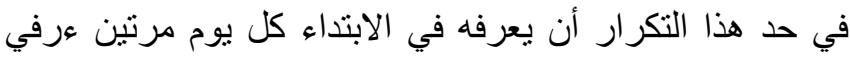

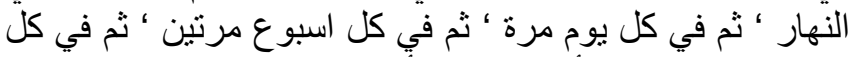

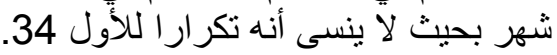

\section{ثانيا: الفورية في التعريف:}

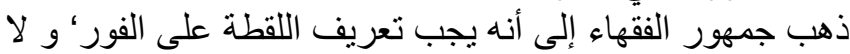

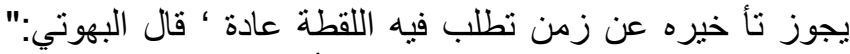

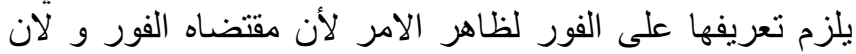

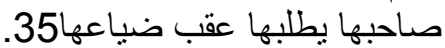

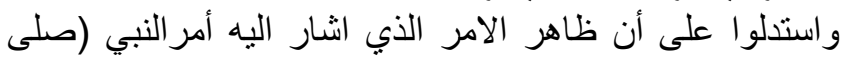

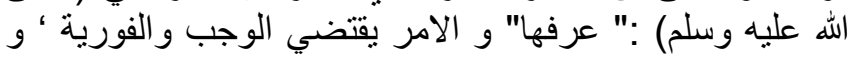

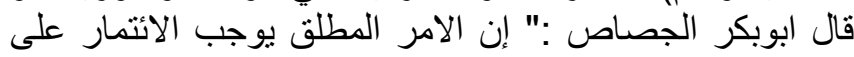

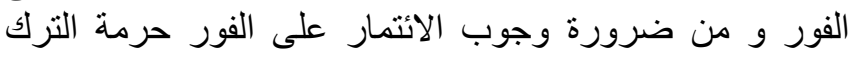
الذي هوضده 36 الأن

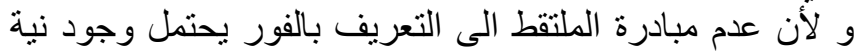

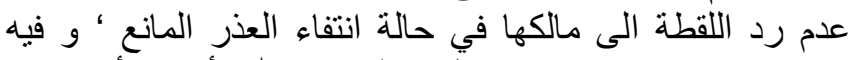

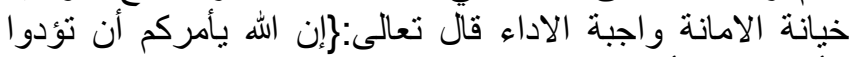
الأمانات إلى أهلهاج

\section{أهلية المعرف وأجرة التعريف: اولا: أهلية التعريف:}

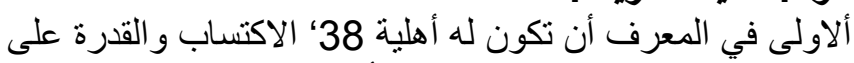

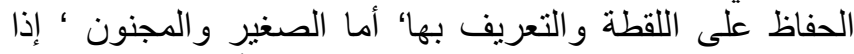

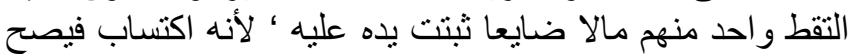

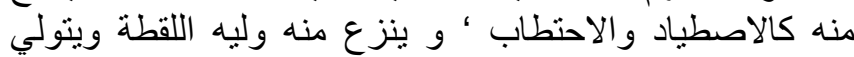

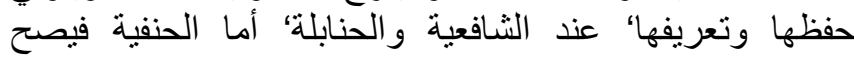

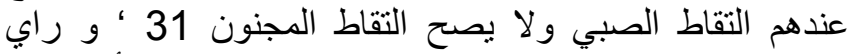

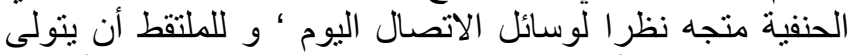

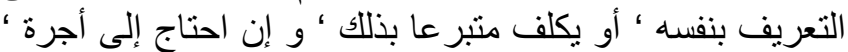

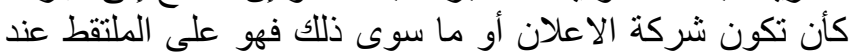

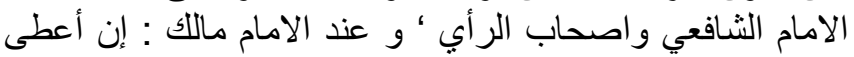

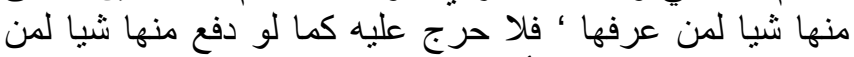

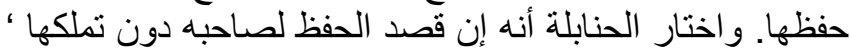

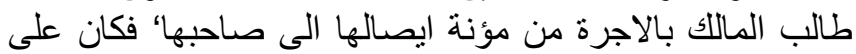

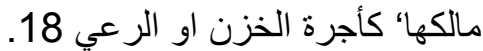




$$
\begin{aligned}
& \text { ثانيا: أجرة التعريف : } \\
& \text { للفقهاء في ذلك أقوال: } \\
& \text { عند الاحناف }
\end{aligned}
$$

فذهب الحنفية إلى أنها على الملتقط لأنه أجر و اجب على ألى المعرف

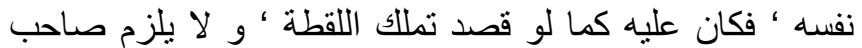
اللقطة بشيء من أجرة التعريف و بكان به قال الحنابلة 39.

عندالمالكية

أما المالكية فيميلون إلى أن ما بنفقه الملتقط من أجرة التعريف بوفي

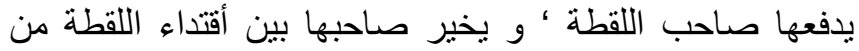

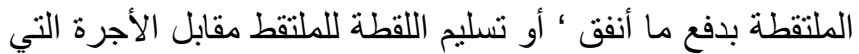

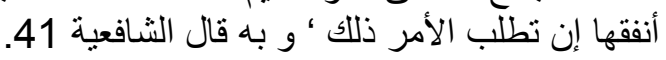
القول الر اجح إنح

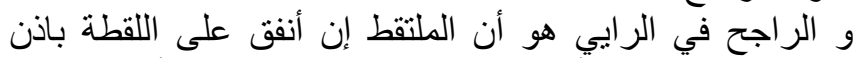

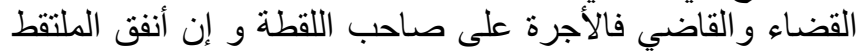

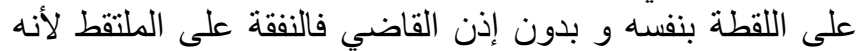

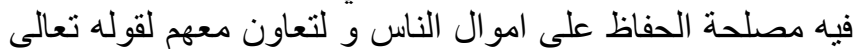

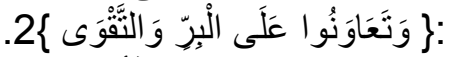

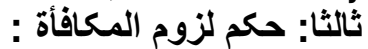

اختلف العلماء في الرجل يرد الضالة بلا إذن صافن صاحبها على أقوال: - (

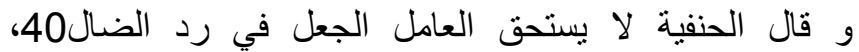

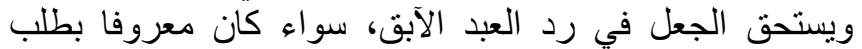

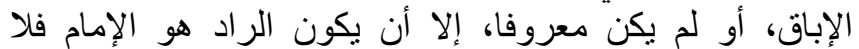

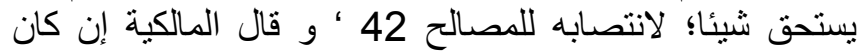

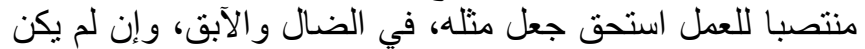
منتصبا للعمل استحق النفقة 41، لأن هذا عمل لم يتفق فيه على فلى

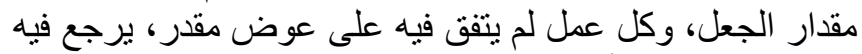

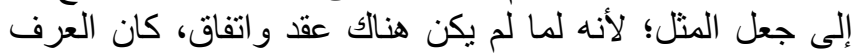

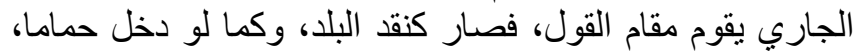

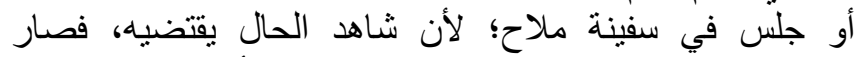

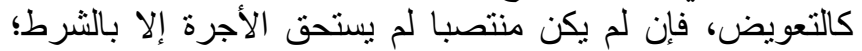

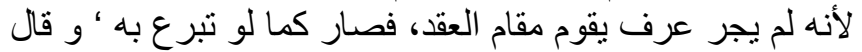

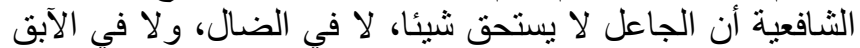

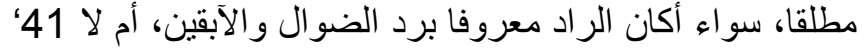

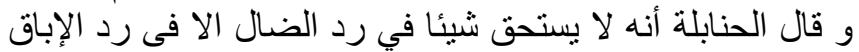

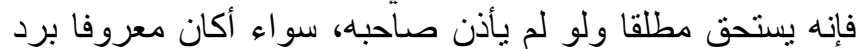

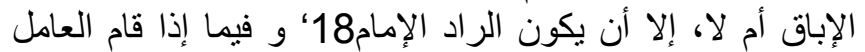

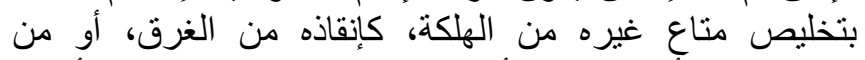

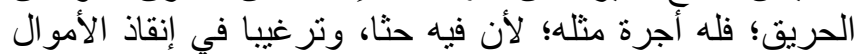

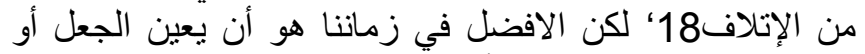

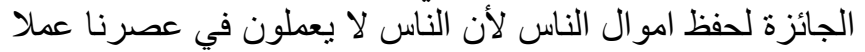
بدون المكافاة.

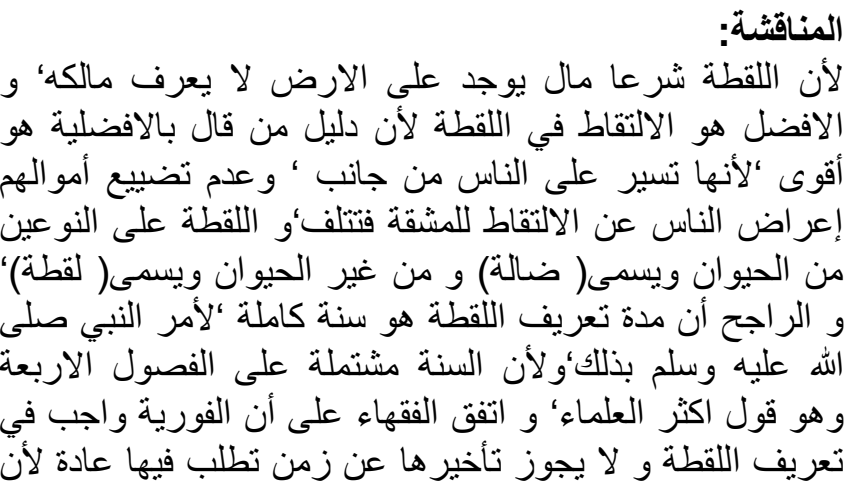

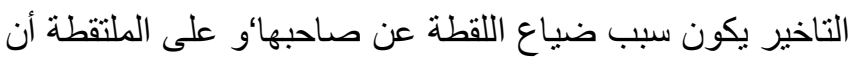

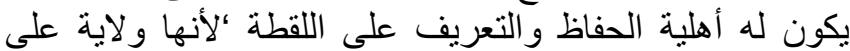

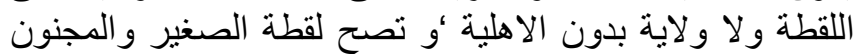

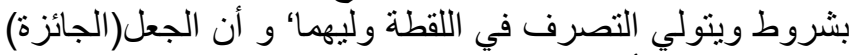

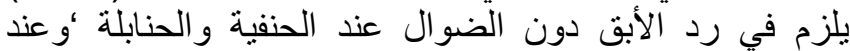

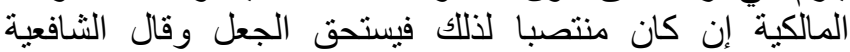

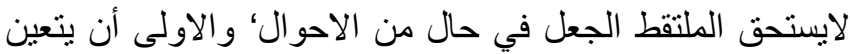

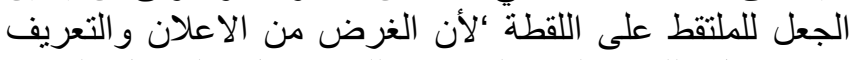

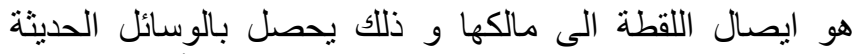

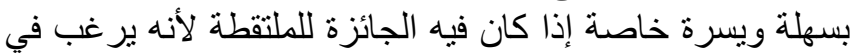
أخذها وحفظها و ايصلها الى المالك.

\section{The Founded Asset (Looqta) \\ Summery:}

Almighty Allah set out for His servants what works for their hearts and bodies and what works for all of their affairs and conditions, and that was the care of the money side, where the street set ways to collect it and ways to spend and spend it and how to preserve it, and it has proliferated The texts indicating the care of funds and mentioning the provisions related thereto. Therefore, a separate chapter under the title of the Founded assets was devoted to it containing provisions based on legal evidence.

And the Founded asets is the money or thing that a person finds in a public place and time and is ignorant of who is its owner and its owner. 'And this money may have a great value or have little value. In any case, it must be found principles and rules by which the money is captured to reach its owner and owner. And among the provisions of the Founded assets is the maximum of its provisions, which is the delivery of the Founded assets to its owner, and that is achieved by announcing the Founded assets after finding it in different parties to verify the assets to its owner and return it to him. In Islamic jurisprudence by presenting legal and juristic rulings that are consistent with the definition of the Founded asset sand ways to use the means around the announcement of the snapshot

And I looked at that through a seat and four demands and results, and mentioned the sources and references in the end. "As for the seat, I showed the importance of the topic, the reason for choosing it and the method of research in it. After explaining the concept of the Founded assets language and terminology 'and the statement of the types of Founded assets and the rule of capture' or the rule of the definition of duty, scarring, permissibility, hatred and sacredness

And a statement of how to define 'and the time period for the definition of the Founded assets and the time of its definition and the promptness in it and the consideration of the jurists about that' and a statement of the eligibility of the identifier and the picker and a statement of the identification fee and a statement of the necessity of the reward for the capture 'and the results include the most important issues about the Founded assets drawn from this research and investigation fourteen limits Resources' In conclusion, he mentioned the sources and references.

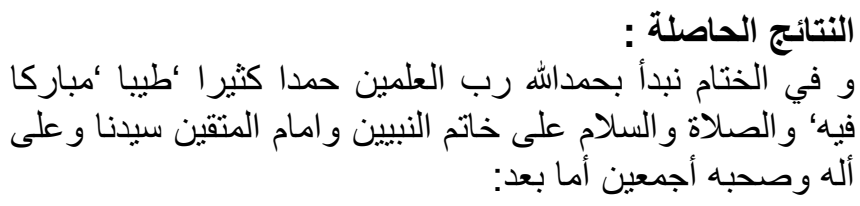


فأهم ما توصلت في أثناءتحقيقي حول الاعلان و التعرف باللقطة

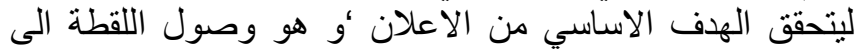

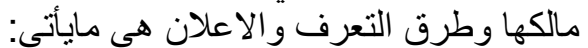
1- تعريف اللقطة واجب باتفاق الفقهاء نظر ا لأهمية اللقطة و واتئ مقدار ها حسب الصوص الثر عية. 2- و التعريف با اللقطة هو إثناعة خبر ها في الناس حتى يصل المبل إلى صاحبها و لا تضيع في أيدي الناس.

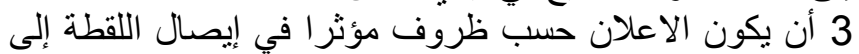
مالكها “لأن الهدف هو الأن الإنال هن الى صاحبها.

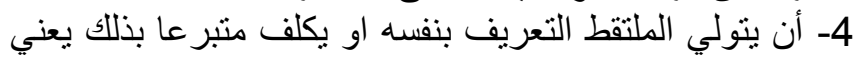
يجوز التوكيل في الاعلان عن التون اللقطة 5- أن تكون اللقطة ذات أهمية فيجب تعريفها واندة ولا يجب تعريفها

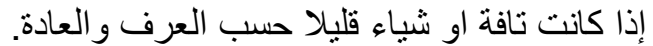
6- الافضل هو أن بجعل له الجعل أو الجائزة فهو أولى بحفظ امو ال الناس في عصرنا. 7-الاعلان عن اللقطة حسب الوسائل الحديثة جائزة و سهلة في ايصال اللقطة الي مالكها. 8- و لأان الايصال اللقطة اللى مالكها من باب تعاون بالبر و الخير و الفلاح.

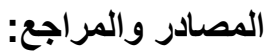
1. الرازي “ابو عبد الله محمدبن ابي بكر ( 1999 )مختار

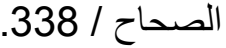
2. احمد مختار'عبد الحمبد عمر (2008) معجم اللغة العربية المعاصرة 2450-244 / 2450. 3. الفيروز ابادي، محمد نعيم العرقسوسي (2441 (2005) القاموس

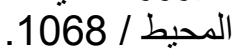

4. المناوي، محمد بن تاج العارفين بن علي بن زين العابدين

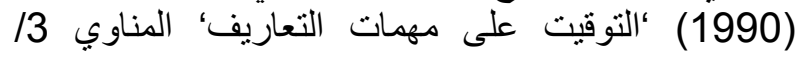
2450 5. الديلمي' دز عمبد جاعد(1998)،التخطيط الاعلامي المفاهيم والاطار العام ، د حمبد جاعد الدليمي 17.

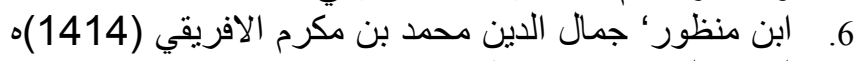

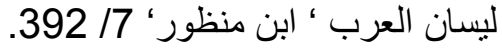
7. 8. النسفي"ابوحفس عمر بن محمد(ب ت)طلبة الطلبة، النسفي/ .93

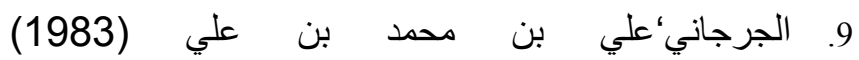

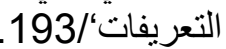
10. قانون التصرفات باللقطة والاموال المتروكة في إمارة دبي

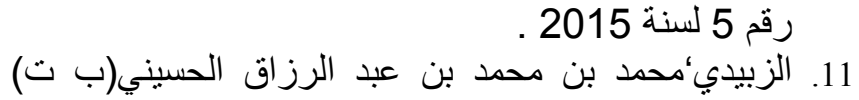

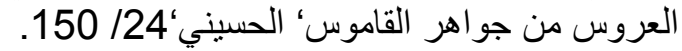

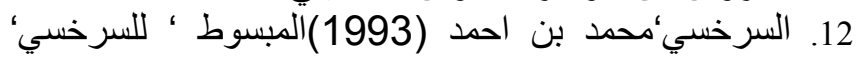
.202/11

13. عطاء ابن السائب الثقفي الكوفي.

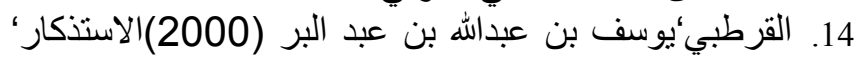

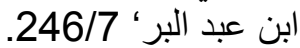
15. ابو محمد سعيد ابن المسيب بن ابن حزن المخزومي المدني.

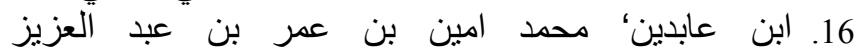
(2000)حاثية رد الختار على الدر الدخدار المختار شرح تنوير

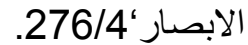

17. الطبراني"ابوالقاسم سليمان بن احمد بن ايوب (ب ت)
المعجم الكبير ‘265/2.

18. ابن قدامة موفق الدين عبداله بن بن احمد (1968)

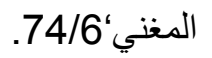

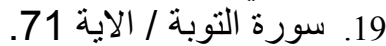

20. ابوداود' سليمان بن اشعثث بن الابن اسحاق الأزدي السجستاني

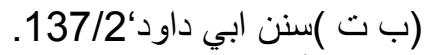

21. ابو عبدالله محمد بن احمد بن محمد دولمد (1989) منح الجليل شرح مختصر خليل، 230/8.

22. العيني“بدرالدين محمود بن احمد (2000) البناية شرح

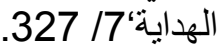

23. البخاري'محمد بن اسمعيل بن ابر اهيم بن المغيرة (1987)، الجامع الصحيح' 8: 84.

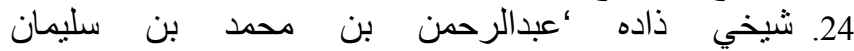
(1994)،مجمع الانهر في شرح ملتقى الابحر، ، 526/2. 25. البيهقي"ابوبكر احمد بن "الحسين بن الاني علي (1344ه) سنن

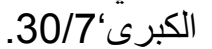

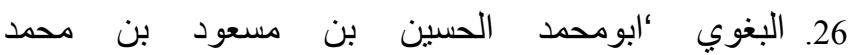

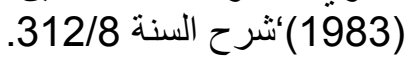

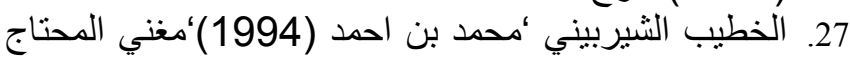

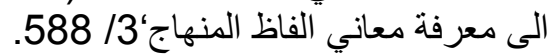
28. ابو عمرو عامر بن شر احيل بن عبد الهمداني الشعبي.

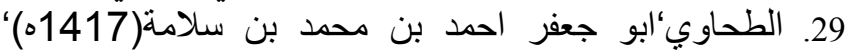
مختصر اختلاف العلماء 336 / 336. 30. سفيان بن سعيد بن مسروق ابو عبداله الثوري.

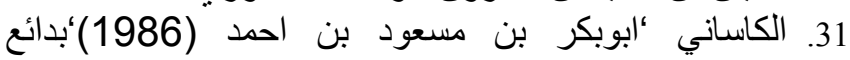

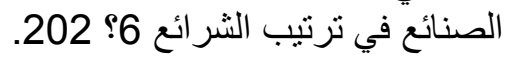

32. ابويعلى"احمد بن علي بن بن المثنى الموصلي (202. (1989)' مسند ابي بعلى 332/2. 3.

33. الشوكاني'محمد بن علي بن محمد (1993)، نيل الاوطار شرح منتقى الاخبار 15 / 404. 34. النووي، محيي الدين بن شرف الإن (1991)؛روضة الطالبين

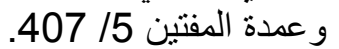
35. البهوتي" منصوربن يونس بن صناح الاح الدين(ب ت)،كثاف القناع 4عن منن الاقناع / 329. 36. البزدوي ، علا الدين عبد العزيز بن الاعن اعد بن محمد البخاري

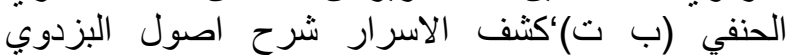
.331/2

37. سورة النسا/الاية 58.

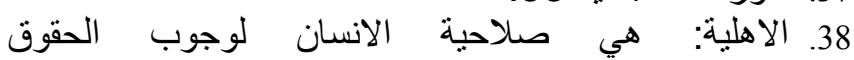
المشرو عة.التعريفات 40. 39. النووي "أبو زكريا محيب الدريفات الدين يحيى بن شرف(ب ت)،

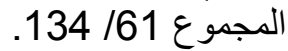
40. الزيلعي، عثمان بن علي بن محجن (1313ه)؛ثبيين الحقائق شر ح كُز الدقائق 3.

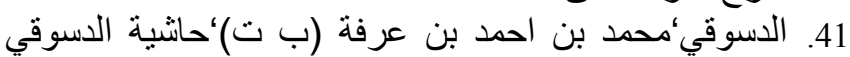

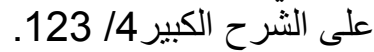

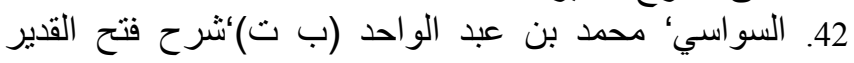
.428/4 